\title{
LA FILOSOFÍA ANTE LA CRISIS. CONSIDERACIONES TEÓRICAS SOBRE LA CRISIS ECONÓMICA
}

\section{JUAN A. GARCÍA GONZÁLEZ*, Universidad de Málaga}

Resumen: ponencia pronunciada por el prof. Dr. Juan A. García González en el I Simposio Jóvenes Filósofos de Málaga celebrado el 17 de abril de 2009 en el Ayto. de Alhaurín de la Torre. En este trabajo se analiza la actual crisis económica desde una perspectiva antropológica que presta atención a la persona, las relaciones interpersonales, la libertad, el futuro y otras dimensiones humanas.

Claridades. Revista de filosofía

Sumary: paper enounced by prof. Ph.D. Juan A. García González at the I Young Philosophers of Málaga Symposium celebrated April 17, 2009 at Alhaurín de la Torre Town Hall. In this work the current economic crisis is analyzed from an anthropological perspective that pays attention to the person, the interpersonal relationships, freedom, future and other human dimensions.

persona, crisis, libertad, futuro

person, crisis, liberty, future

\section{PRESENTACIÓN}

Seguro que hoy, reunidos aquí para tratar de la tan manida crisis que nos afecta, vamos a escuchar ideas y propuestas muy interesantes. Sé que alguno va a decir que crisis como la actual son en el fondo crisis de la teoría, de la supremacía del pensar humano, marginado hoy por una imperante actitud pragmatista. Sé también que otros van a decirnos que crisis como la presente son en definitiva crisis de valores, expresión de la desorientación humana ante la diversidad y variabilidad de los tiempos presentes, es decir, ante la complejidad de nuestro mundo actual. Y otros finalmente nos dirán que la crisis es fundamentalmente económica, y que es al liberalismo y al capitalismo económicos a los que hay que acudir para entenderla y solucionarla. Me consta que de esto y de mucho más vamos a hablar aquí.

Pero yo les voy a proponer que lo propiamente crítico es la libertad humana; porque a ella le corresponde aprobar o rechazar: sí o no; y cuando dice

\footnotetext{
*jagarciago@uma.es
} 
no... se aventura tormenta. Kierkegaard, que era un buen psicólogo y conocedor de la humana naturaleza, tituló uno de sus escritos Aut, aut (Enten-Eller 1843) que se ha traducido como 0 lo uno o lo otro. Yo creo que aún es mayor la alternativa propia de la libertad personal: es el sí o el no; la afirmación y la admisión, o la negativa y la catástrofe.

Por ejemplo, yo, cuando me jubile -si llegare a ello-, quizá quiera vender mi casa, ésa que llevo pagando buena parte de mi vida. Y entonces, si alguien me dice que sí, que me la compra, tendré una jubilación plácida; pero si todo el mundo dice no, y no la puedo vender, me quedaré con mi pensión malviviendo: estaré en crisis.

Lo crítico, digo, es la libertad. Ello es compatible con el hecho de que además la economía sea cíclica, y a una temporada de vacas gordas, solemos decir, suceda otra de vacas flacas. Yo creo que, efectivamente, esto es intrínseco a la economía: porque la riqueza se produce... y se gasta; y se vuelve a producir... y se vuelve a gastar. Siempre hay primeros de mes, y finales. Algo así pasa también hoy: ¿cómo se van a vender tantos coches como se vendieron los años inmediatamente pasados, si ya la mayor parte de los conductores cambió de coche?, ¿cómo se van a seguir vendiendo casas, si casi todo el mundo tiene ya una?, o ¿cómo se van a seguir vendiendo móviles, si hay ya más de uno por persona?

La actual crisis económica es compleja, pero uno de sus factores es, sin duda, éste: hemos llegado a un cierto tope, porque la economía atraviesa ciclos. Quizá, por ejemplo, en el desarrollo de las nuevas tecnologías de la comunicación (informática, móviles, digitalización del mundo multimedia, etc.), que han activado la economía estos últimos años, se haya llegado a un tope (aunque en España aún no he visto, como en América, teléfonos con doble tarjeta, para usar con dos operadoras). Por eso el G-20, en su última reunión, decidió impulsar las energías renovables como foco de activación económica; habrán oído hablar de ese inmenso parque marino de aerogeneradores que el Reino Unido planea cerca de Escocia. Obama también piensa en algo similar.

Con todo, insisto, lo crítico es la libertad; y la economía atraviesa crisis porque es algo humano, que queda bajo la libertad, y no es una realidad técnica o física, que se componga de cosas: productos, balances, redes de distribución, mercados, etc.; sino algo humano, de relaciones interpersonales. Teorizaré un poco para profundizar en esto.

\section{LA PERSONA Y LAS RELACIONES INTERPERSONALES}

Si comparamos el ser con la acción, creo que tendremos que distinguir dos clases de seres. Unos, los seres naturales, son aquellos que para 
mantenerse en el ser necesitan actuar; aquellos que actúan de tal modo que sin la acción no son, porque -por decirlo así- son lo que hacen. La naturaleza, en efecto, se define como el principio interno del movimiento; es un dinamismo que da lugar, que hace nacer, cosas; o una causa que tiene unos efectos. Dejar de actuar es, para los entes naturales, dejar de ser.

Pero las personas somos seres que no nos reducimos a nuestra acción; la ejercemos si queremos, y si no, no; y aunque la hagamos, no nos agotamos al hacerla, no nos reducimos a la conducta, ni consistimos en desplegar un papel. La acción humana puede, en efecto, ser simulada, o puede también ser rectificada; muestra en ello que se separa de la persona. La persona se reserva respecto de su acción; así es dueña de ella, y por eso es libre.

No es libre, porque produzca su acción igual que los seres naturales, pero libremente, sin fundamento o razón previa, sin causa antecedente. Es libre, porque desborda su acción, no se agota ni se mide por ella. La pone si quiere; y lo haga o no, ella queda un tanto al margen de lo hecho.

¿Por qué ocurre esto? ¿Para qué la persona se reserva y distancia respecto de su acción? ¿Qué sentido tiene la libertad humana? Todo esto ocurre para que la persona se abra a la coexistencia interpersonal. Y, por enmarcarse en esa coexistencia, las acciones humanas tienen un sentido peculiar, de intercambio entre personas que coexisten. Al actuar hacemos algo para alguien. Y esto inevitablemente; quiero decir, por muy egoísta que uno sea: lo que hace siempre tiene destinatarios, afecta a los demás, se produce en un ámbito social. La acción en la naturaleza no se explica sin causa, sin agente. En cambio, la acción humana cuando no se explica es más bien si carece de destinatario, si no repercute en nadie. El sentido, pues, de la libertad, de que la acción humana no sea un despliegue mecánico o automático del sujeto, es éste: la apertura a la relación interpersonal.

Estas someras consideraciones antropológicas vienen a cuento de que la economía es una ciencia humana, estrictamente humana; porque precisamente es la ciencia que versa sobre un tipo de relaciones interpersonales, las mediadas por el dinero.

Aristóteles, sin entenderla como lo hacemos hoy porque la reducía a un ámbito meramente doméstico, en cambio la sitúa como una continuación de la ética individual: ética, economía y política son las ciencias prácticas. La economía es, pues, una ciencia práctica; que trata de la acción humana, y tiene un referente colectivo. Si la persona lo es en orden a establecer relaciones personales, la economía es entonces una ciencia muy humana, o un arte enteramente liberal, una parte muy importante de la antropología.

Como ciencia humana que es, la economía no es un saber matemático, una ciencia exacta; ni un saber sobre las cosas. Esa definición de la 
economía como la administración de recursos escasos, porque si la riqueza fuera abundante no habría por qué economizar, es en mi opinión completamente inadecuada. La economía es una ciencia humana, porque se ocupa de un tipo de relaciones interpersonales, aquéllas que están mediadas por el dinero. No todas las relaciones humanas son económicas, pero algunas sí: aquéllas en las que hay dinero por en medio; que lo haya, no debe ocultar que se trata de relaciones entre personas.

Que el dinero medie en las relaciones personales es algo que puede extrañar, e incluso verse como malo, inconveniente. No solemos entender, por ejemplo, como parecidas, o no nos merecen el mismo juicio, las relaciones sexuales contraídas en el seno del matrimonio, por amor o para engendrar, que las llevadas a cabo por dinero. Seguramente no todas las relaciones personales puedan someterse a precio, y a economías. Pero algunas sí. El dinero no ennegrece las relaciones entre las personas, sino que es imprescindible en muchas de ellas.

\section{EL DINERO}

Conviene entonces que pensemos un poco en el dinero.

No acepto esa acusación de materialismo con que se desprecia el vil metal. Lo materialista quizá es el trueque, el intercambio de cosas unas por otras. Pero precisamente el dinero es un ente ideal para equilibrar los intercambios. Como la palabra, es un instrumento universal, que nos permite homologar cosas heterogéneas. Y, como la palabra, por ser ambas cosas ideales, el dinero está en el orden de la posibilidad; más que la realidad del billete de papel, como más que las letras que la palabra contenga, lo importante es el significado. Lo propio del dinero son las posibilidades que permite: lo que se puede pagar con él.

\section{a) Formas de dinero:}

Suele decirse que hay tres clases de dinero: el monetario, el financiero y el capital.

El dinero monetario es el dinero más real, quiero decir el dinero actual: billetes y monedas. Observaré que antiguamente, y según cierto ideal, ese dinero se correspondía con las reservas acumuladas en un depósito: con el oro u otras propiedades de valor. Muchas denominaciones de monedas tienen que ver con ello: el peso, la peseta, la onza, la libra (pound), la lira, etc. Hoy, en efecto, acusamos a los bancos de prestar más dinero que el que tenían, o a las empresas de invertir más capital del que podían respaldar. 
El dinero financiero, en cambio, es en cierto modo irreal, inexistente; es el apunte contable: entradas y salidas. Como ingreso diez en el banco, me cobran tres de un recibo, tres de otro y tres de un tercero, sólo me queda uno. Pero en el banco no siempre hay dinero en efectivo; porque las entradas y salidas se compensan con otras salidas y entradas, y a veces todo queda en nada. Para eso existen las cámaras de compensación interbancarias. Y cuando el Madrid ficha a Woodgate del Newcastle por 20 millones de euros, y al año siguiente vende a Owen al Newcastle por otros veinte, lo más probable es que no se haya movido ningún dinero real. O si el Newcastle debía a la Juventus, y ésta al Oporto, lo que el Oporto debía al Madrid; es incluso posible que haya fichajes entre clubes al solo objeto de saldar cuentas pendientes.

Finalmente el capital es el dinero que genera dinero. La diferencia entre la agricultura y la ganadería es ésa: que el terreno produce frutos; y quizá se le pueda sacar más partido a un terreno multiplicando el número de cosechas al año, o mejorando artificialmente el fruto, pero el terreno sigue siendo el mismo. En cambio, el ganado no sólo da sus productos -la leche, la lana, etc.sino que se reproduce, y se incrementa numéricamente: crece y se amplía. Pues con el dinero ocurre lo mismo, como descubrieron los judíos hace mucho tiempo: que, con intereses, puede aumentarse la provisión inicial y capitalizarse.

Parece ser que Marx, de los primeros -y más primitivos- teóricos del capital, ordenó estas tres formas de dinero en el orden en que las he enunciado: dinero efectivo, financiero y capital. Por eso pensó que la plus valía del empresario, no sólo era injusta, sino proclive a acumularse reduciendo el número de sus poseedores, de los capitalistas, hasta que fueran tan pocos que se produjera la revolución y llegara la sociedad sin clases.

$Y$ parece ser también que el tiempo ha demostrado que esas tres formas de dinero se han ajustado según otro orden: primero el dinero monetario, después el capital y finalmente las finanzas, el dinero más irreal y nominal. Nuestra crisis económica actual es una crisis financiera. Hablemos un poco de ello.

Decimos que lo propio del dinero, como algo ideal que es, son las posibilidades que permite. El dinero está en el orden de la posibilidad; y en ello muestra ser una obra del espíritu, y no una realidad material. Como ficción ideal que es, el dinero modula el tiempo de una curiosa manera.

\section{b) Dinero y tiempo:}

Con el dinero se produce, básicamente, una mudanza del presente por el futuro. Porque al trocar una cosa por otra, cambiamos un presente por otro: tenía un bolígrafo y se lo he cambiado a mi compañero por el suyo: ahora 
tengo otro bolígrafo. Pero si en vez del trueque material, asigno un precio a mi bolígrafo, pongamos $5 €$, y lo vendo; entonces he cambiado mi presente por un futuro posible: porque con los $5 €$ yo podré tomar un café, pagar el aparcamiento, comprar un lápiz en vez de un bolígrafo, o lo que sea.

Incluso más: el dinero no sólo muda presente por futuro, sino pasado por futuro. Porque me habrá costado un tiempo conseguir las propiedades que pongo en venta. Las cosechas son anuales, o quizá semestrales: tardan un tiempo en lograrse. Luego se venden y el agricultor puede vivir la temporada siguiente. El petróleo ha tardado siglos en formarse; es un pasado demasiado largo como para volverlo a producir; y por eso no podemos dilapidarlo: su consumo es limitado, porque las reservas se agotarán.

Presente o pasado se mudan por futuro. La forma más elemental de capitalización es ésa: la futurización. Si no sólo compro tu producción actual, sino la futura, la de los próximos años, he creado un valor irreal; porque la producción futura es aún inexistente. Pero este tipo de capitalización está a la orden del día.

Por ejemplo, durante el pasado año el precio del petróleo osciló de 50 dólares por barril hasta alcanzar los 150, y luego volvió a bajar hasta los 50 en que más o menos está; y que por lo demás se corresponde mejor con el coste de producción. ¿A qué fue debida esta oscilación? Inicialmente la subida del crudo se achacó a China; porque el automóvil se está extendiendo en aquél país hasta las clases medias, como en España se extendió el seat 600 en los años 60. Además se están popularizando coches muy antiguos, de gasolina, sin catalizador, contaminantes (China tiene por ello un gran problema de contaminación); por consiguiente consumen mucho petróleo. Pero la causa del alza del petróleo, que triplicó su valor en seis meses, fue otra: fueron los especuladores de Wall Street. Que, en lugar de comprar el petróleo necesario para una empresa, para sus refinerías y gasolineras, compraron a futuro: cierta producción pero comprometida para los próximos cinco o siete años (y eso que sólo pagaban en efectivo los barriles que se llevaban en el acto). Luego, con ese contrato plurianual mercadeaban en la bolsa, sacando beneficios a cambio de asegurar crudo para años venideros. Es una fácil capitalización: la inclusión del futuro; si uno tiene trabajo asegurado, una nómina, es más fácil conseguir un crédito. Y entonces ¿por qué el precio del petróleo volvió a bajar? Pues porque un especulador no pudo vender, o perdió dinero. Quizá simplemente porque el presupuesto de adquisiciones de las empresas petrolíferas se había agotado, ya que tenían sus almacenes llenos. Y si una operación financiera falla, la siguiente está herida de muerte; hasta que el petróleo recupera su precio normal.

Presente o pasado se mudan por futuro. Pero resulta que el dinero financiero, contable, es en cierto modo inverso al dinero monetario, efectivo. Porque cuando uno trabaja un mes, le pagan su salario, y así puede vivir el mes 
siguiente. Pero cuando uno financia algo, por ejemplo avala con su nómina la compra de un coche, entonces con su trabajo futuro, y con su futuro sueldo, dispone de un coche ya. Gasta un futuro para una realidad presente. Algunas hipotecas americanas, que a punto estuvieron de llegar a España, eran a cuarenta o más años, y estaban concebidas para que incluso cuando te murieras, tus hijos decidieran si querían seguir con esa casa o renunciar y dejarla en manos del banco. Un futuro quizás excesivo.

El caso es que en la primera mitad del siglo veinte, la gente ahorraba, acumulaba pasado, con la intención de dejar una pequeña herencia a sus sucesores. No quería consumir innecesariamente. Cuando a mi abuelo le dije que me iba a la calle a tomar un café, me respondió: ¿qué pasa, es que no hay café en casa? Reprobaba lo que consideraba un consumo excesivo. En cambio hoy, más bien, la gente se hipoteca y vive del futuro. Quiere vivir, gozar de las cosas, ya, y él; mejor que posibilitar la buena vida de sus herederos. Aunque lo cierto es que buena parte de los ricos que conocemos lo son por sus predecesores (otros quizá por negocios, y otros por circunstancias).

El dinero financiero, digo, es una mudanza del futuro en presente; con las finanzas conseguimos invertir el sentido del tiempo. Quizá no tanto como ese túnel del tiempo que el hombre imagina a veces en la ficción: el retorno hacia el pasado; pero sí la presentificación del futuro. No me explico cómo, observando esto, algunos científicos siguen negando la causa final por no comprender cómo el futuro puede incidir en el presente; quizá es que no tengan ninguna letra.

\section{PRECIO Y CONSUMO}

Pero volvamos al tema. El dinero media en ciertas relaciones entre las personas: se paga a cambio de un bien o servicio. Hasta tal punto, que esos bienes o servicios no valen nada fuera de la relación interpersonal. Por llamativo que esto resulte, y por poco que lo tomemos en cuenta, es tan claro como patente. El valor de una cosa -su valor económico, claro está- no remite a lo que cuesta conseguir que exista, sino exclusivamente a lo que los demás están dispuestos a pagar por ella.

Ese hiperrealismo que considera que hay un valor en sí mismo de las cosas, quizá lo que costó conseguirlas, no atiende a lo más evidente: que siendo la compra-venta una relación entre personas, si nadie quiere pagar por algo, ese algo no vale nada; o nada más que lo que alguien quiera pagar por él.

Esto es algo especialmente importante hoy, cuando valores hipotecarios y financieros han decaído muy llamativamente. Las acciones de algunos grandes bancos norteamericanos e ingleses se han devaluado un $80 \%$ en 
el último año: ¡esto es una barbaridad! Realmente incomprensible; nos estamos dejando llevar quizá de un pánico muy perjudicial (toda relación interpersonal sucumbe si se establece sobre el miedo); o bien realmente nadie tiene dinero liquidez dicen- para comprar esas acciones y esperar a que recuperen su valor. Pero es que no sólo son los bancos o las constructoras, sino que las diez mayores fortunas del mundo han perdido mucho en el último año, alguna casi la mitad de su valor. La bolsa española -y esto afecta a miles de accionistas, yo conozco alguno- ha caído un 30 \%. La crisis no sólo afecta a los pobres, generando paro en la construcción, llevando a la quiebra a concesionarios locales de automóvil, o a pequeños comercios; sino que afecta más a los más ricos (creo que si no, no sería crisis). Puede sorprendernos la caída de los grandes; pero no más que ver desaparecer esa famosa cafetería de la calle Larios, la cosmopolita: se reduce a que si la gente no quiere tomar ahí café... ¡qué le vamos a hacer!

Con estos ejemplos quiero llamar su atención hacia el hecho de que las cosas no valen por sí mismas, sino por lo que la gente con la que intercambiamos las aprecia. Mi casa, aunque me haya costado $100.000 €$, no los vale; valdrá, dado el caso de que la ponga en venta, lo que quieran dar por ella en ese momento. Yo tomé el otro día unos ganchitos, me parece que les llaman unas chucherías de maíz-, por los que pagué 25 céntimos. Desde luego, nadie puede producir nada con tan poco dinero, y ese precio sólo se explica porque producen una cantidad ingente de paquetes de ganchitos, para todos los kioskos, de todas las calles, de todas las ciudades y pueblos. Pero no podrían tener otro precio, porque los niños no pueden pagar lo que los ganchitos eventualmente pudieran costar.

Las cosas no valen por sí mismas, porque se insertan en el intercambio económico entre personas. Esta inserción no es otra cosa que el consumo.

A veces se ha tachado a la actual sociedad de consumo de inmoral, de materialista; de injusta, habiendo tanta pobreza en algunos lugares del planeta. Pero el consumo tiene una dimensión objetiva, y no sólo la vertiente subjetiva de la inmoderación individual con que con frecuencia lo entendemos. Esa consideración objetiva dice que el dinero ha de circular como motor de la economía, creador de riqueza y trabajo. La inmovilización del dinero paraliza la actividad económica, rompe las relaciones interpersonales. No sólo es que yo guarde dinero en un cajón, y así me enriquezca; es que, al no usar el dinero, fracturo relaciones interpersonales posibles; por lo menos, de momento. Por ejemplo, a veces se considera un lujo tomar un taxi, especialmente si no hay prisa; sorprendente, cuando no se considera en cambio un lujo tener un coche propio. Pero si no usamos el taxi, los taxistas no podrán vivir, o vivirán mal; y serán caros; luego, no nos podremos extrañar de que con frecuencia abusen, e intenten sacar algo más de lo que les corresponde. Las cafeterías se cierran, los periódicos quiebran, los comercios despiden empleados... pero nosotros: 
¿tomábamos café en esas cafeterías?, ¿comprábamos esos periódicos?, ¿adquiríamos algo en esos comercios? Hay un ministro que pidió que compráramos productos españoles para beneficiar la economía nacional. No sé si es preciso, pero se inscribe en esta consideración objetiva del consumo que intento señalarles.

\section{POLÍTICA Y ECONOMÍA}

En suma, he querido decir que lo crítico es la libertad, porque la economía remite a la persona; ya que el dinero es una entidad ideal para facilitar el intercambio, que da lugar al consumo, y por eso el precio remite al comprador. En definitiva, la economía remite a la libertad porque trata de relaciones personales. Y entonces, como el gobierno de las personas es la política, lo que la economía necesita, por ser liberal, por humana, es política económica.

Dicen que esta crisis que vivimos es la crisis del capitalismo, del modelo neoliberal que imperó con Tatcher, Bush y Aznar. Pero yo veo lo contrario: que es la rendición del estado al capital; que todos los gobiernos, socialistas o conservadores, europeos y americanos, prestan sus servicios al capital, reconociendo su necesidad para la buena marcha de las economías locales, y de la mundial. Pero entonces no es la crisis del capitalismo, sino la crisis del estatalismo: que se declara necesitado del capital. Nuestros gobernantes temen el paro, la recesión, la inactividad económica; y rinden pleitesía al capitalismo incluso apoyando con dineros públicos a empresas y bancos que hubieran quebrado sin ese apoyo. No es más que una proyección de su habitual intervencionismo, tan fuera de lugar normalmente que llama la atención que no se hayan dado cuenta de ello. Como si las relaciones personales dependieran del arbitrio de los gobernantes.

Si la economía trata de relaciones personales, y si es la libertad lo crítico, entonces no necesita tanto balances matemáticos, planes de estabilización o proyectos de inversión, cuanto políticas adecuadas. Política es el convenir los futuros humanos, y su falta -se me ocurre- es el gran detonante de la crisis financiera y económica en que nos encontramos.

Porque los estados carecen en términos generales de política económica; o más bien la tienen: es la de Alí Babá, el reparto del botín. De ese botín que son los impuestos, que sustraen de los haberes de los ciudadanos sin contar con su voluntad, y luego dedican a lo que quieren, por lo común con derroche e ineficiencia. La derecha dedicará el botín a las obras públicas: jardines, acerado, etc. (Villalobos llegó a la alcaldía de Málaga, y se puso a limpiarla; quiero pensar que porque estaba sucia, no por ser mujer). En cambio, la izquierda, como tiene más sensibilidad social, tiende a crear gabinetes de 
protección a las mujeres maltratadas, servicios de atención a los inmigrantes, o a financiar el aborto en hospitales públicos, o a lo que sea. Repartimos el botín de uno $\mathrm{u}$ otro modo.

Pero reducir la política económica a eso es pobre y triste; casi diría mezquino. La política económica es la política empresarial, la que crea futuros; y no compete tanto a los gobiernos cuanto a los empresarios y capitalistas. Ellos, las veinte empresas más grandes del mundo, y no el G-20, son los que debían reunirse para ver qué hacer ante la crisis. Hay 14 empresas norteamericanas que facturan más de 100 millones de dólares por año; y hay 21 bancos en el mundo con más de un billón (millón de millones) de dólares en depósitos. Ellos deberían intervenir. Y, mientras no lo hagan, no saldremos de la crisis.

Las medidas tomadas por los estados, tan celebradas por los interesados (se gastaron 300.000 dólares en una cena y orgía esos banqueros rescatados en Norteamérica), son -en boca del venezolano Chavez- las mismas medicinas que están matando al enfermo.

\footnotetext{
$* * * * *$

Juan A. García González es doctor en filosofía y profesor titular de filosofía en la Universidad de Málaga.

Publicaciones recientes:

Y además. Delta, San Sebastián 2008.

Antropología y trascendencia. Universidad, Málaga 2008

La doctrina de Polo acerca de la luz y su papel en el universo y para la vida. "Studia poliana" Pamplona 11 (2009) 61-93.

Conocimiento y libertad en el plano operativo y en el plano existencial. "Themata" Sevilla 41 (2009) 483-9.

Líneas de investigación:

Instituto de estudios filosóficos Leonardo Polo

Grupo de investigación sobre el idealimso alemán: Schelling

Pensamiento de Levinas

Dirección postal:

Departamento de filosofía. Universidad de Málaga. Campus de Teatinos s/n 29071

MALAGA

Dirección virtual:

jagarciago@uma.es
} 
proceso de selección del trabajo:

solicitado: 1 de enero de 2009

recibido: 15 de abril de 2009

aceptado: 15 de abril de 2009 